\title{
Recursos humanos em saúde mental, álcool e drogas: Formação e competências nas Américas*
}

\author{
Elizabeth Esperidião ${ }^{1,2}$ \\ (i) https://orcid.org/0000-0002-9284-6243 \\ Maria Giovana Borges Saidel2,3 \\ (D) https://orcid.org/0000-0002-3259-1760 \\ Jeferson Rodrigues ${ }^{2,4}$ \\ (D) https://orcid.org/0000-0002-8612-9088 \\ Sônia Barros ${ }^{2,5}$ \\ (iD) https://orcid.org/0000-0002-6346-9717
}
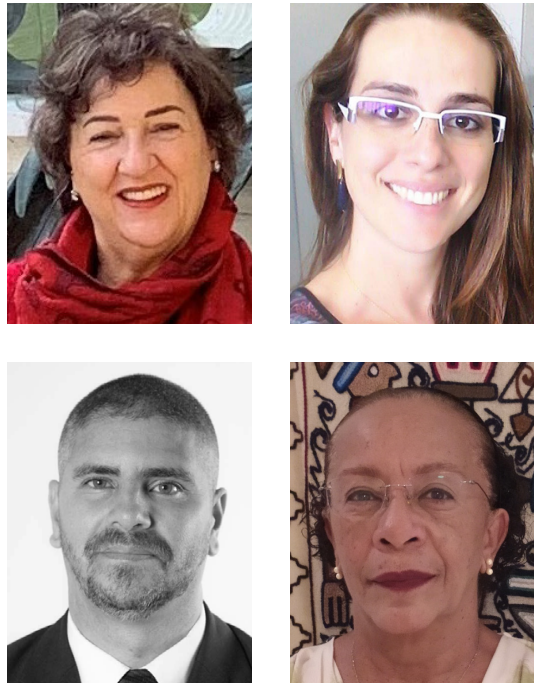

com usuários, familiares, comunidade e entre os profissionais. É imperativo rever formas de gestão, relações

\footnotetext{
* A publicação deste artigo na Série Temática " Recursos Humanos em Saúde e Enfermagem" se insere na atividade 2.2 do Termo de Referência 2 do Plano de Trabalho do Centro Colaborador da OPAS/OMS para o Desenvolvimento da Pesquisa em Enfermagem, Brasil.

${ }^{1}$ Universidade Federal de Goiás, Faculdade de Enfermagem, Goiânia, GO, Brasil.

${ }^{2}$ Associação Brasileira de Enfermagem, Departamento de Enfermagem Psiquiátrica e Saúde Mental, Brasília, DF, Brasil.

${ }^{3}$ Universidade Estadual de Campinas, Faculdade de Enfermagem, Campinas, SP, Brasil.

${ }^{4}$ Universidade Federal de Santa Catarina, Departamento de Enfermagem, Florianópolis, SC, Brasil.

${ }^{5}$ Universidade de São Paulo, Escola de Enfermagem, Departamento de Enfermagem Materno-Infantil e Psiquiátrica, São Paulo, SP, Brasil.
}

\section{Como citar este artigo}

Esperidião E, Saidel MGB, Rodrigues J, Barros S. Human resources in mental health, alcohol and drugs: Training and skills in the Americas. SMAD, Rev Eletrônica Saúde Mental Álcool Drog. 2021 jul.-set.;17(3):4-6. doi: https://dx.doi.org/10.11606/issn.1806-6976.smad.2021.000178 
de poder e separação entre o pensar e o fazer. A qualificação do trabalho profissional se torna, portanto, um dos elementos fundamentais para a construção de um projeto de assistência integral(1).

O cuidado em saúde mental, que envolve aspectos de formação profissional nos âmbitos generalista e especialista, jurídico-político, sociocultural e valores éticos tem passado por transformações elementares. As práticas comunitárias e territoriais em substituição ao tratamento manicomial e institucionalizado são tendências mundiais. Na América Latina e Caribe, essa transição foi sinalizada pela Declaração de Caracas em 1990, cujo documento criticou fortemente o modelo hospitalocêntrico por não articular seus objetivos com a atenção em saúde descentralizada, participativa, integral, contínua e preventiva(2).

Ainda na esteira das mudanças, há de se refletir que a formação de recursos humanos e suas competências para o cuidado em saúde mental estão imersos em estrutura econômica, social e política de cada país. Essa disposição está atrelada às condições de trabalho tanto no setor saúde quanto na educação, podendo enfrentar precarização e/ ou qualificação, a depender do interesse das discussões políticas e da sociedade civil organizada.

É esperado que a formação profissional considere o aspecto técnico necessário à viabilização do trabalho específico como componente capaz de sustentar intervenções práxicas na atividade profissional. A estratégia para efetivação de tal afirmativa centra-se na condução de três vertentes simultâneas: âmbito interno da Universidade; inserção da Universidade nos serviços de saúde; relação da Universidade e serviços de saúde com a população(1).

No que se refere a diretrizes para se pensar globalmente no âmbito das Américas, considera-se que há diversidade inquestionável no que diz respeito às diferenças e semelhanças no sistema político, configurações de território, condições sociais e sanitárias. Ainda assim, uma análise dos programas voltados à saúde mental, objetivando a planificação das ações, atender demandas dos gestores, formadores de recursos humanos e trabalhadores da saúde, daria subsídios para um projeto de formação em saúde mental para as Américas(3). Esse processo de análise possibilitaria reflexão e intervenção sobre as diretrizes da formação profissional do campo da saúde mental, álcool e outras drogas, enfatizando competências necessárias e esperadas.

Os processos formativos, as ações de educação permanente ou em serviço nem sempre se mostram eficazes para a mudança do fazer profissional, devido muitas vezes à descontextualização com a lógica psicossocial e/ou por estarem voltados apenas para a transmissão de conhecimentos em uma perspectiva unidirecional(4).

Especificamente no Brasil, estudo com gestores e trabalhadores da saúde mental demonstrou necessidade de adequação dos currículos (ensino pautado em paradigmas coerentes com a reforma psiquiátrica e práticas e estágio em serviços substitutivos de saúde mental), investimentos na educação permanente e aperfeiçoamento na formação do trabalho em equipe. Essas mudanças estruturais tendem a favorecer para que as práticas ofertadas nos serviços gerais e especializados mantenham consonância com os preceitos da Reforma Psiquiátrica(5).

Todos os níveis de formação requerem articulação do conhecimento com o desenvolvimento de competências interpessoais, intrínsecas ao cuidado em saúde mental. Competências relacionais e de comunicação, trabalho em equipe, iniciativa, cooperação, valores, crenças e atitudes, precisam ter espaço garantido na formação de recursos humanos, na perspectiva de formar pessoas conscientes de seu papel ético, cidadão e social.

No Brasil, a despeito de diversos avanços nas políticas públicas sobre álcool e outras drogas, vários são os obstáculos para consolidar o modelo de atenção integral à saúde. O que permanece ainda, é a lógica repressiva e segregadora em ações higienistas e moralistas. Esses movimentos estão na contramão das estratégias de redução de danos, as quais elegem ações de prevenção e atenção, respeitando singularidades do indivíduo, acolhimento, vínculo, respeito aos seus desejos e escolhas(6).

Destaca-se ainda a necessidade do aumento de financiamento das políticas de cuidado em saúde mental na América Latina e Brasil, objetivando neutralizar estigmas estruturais por meio da assistência de qualidade(7). Outra conjuntura importante é a adoção dos Objetivos de Desenvolvimento Sustentável (ODS). Países que ampararam os ODS comprometeram-se mais com ações de promoção da saúde mental e prevenção dos transtornos mentais. Embora "nenhuma saúde sem saúde mental" seja uma importante aspiração, reconhece-se que por muitos anos a saúde mental permaneceu nas sombras dos sistemas de saúde. Espera-se fomentar parcerias governamentais para transformar a saúde mental, globalmente, envolvendo atores importantes que estejam genuinamente comprometidos ${ }^{(8)}$. Ações eficazes no campo da saúde mental mostram-se ainda mais necessárias, especialmente, num momento em que o mundo todo sofre consequências da pandemia pelo coronavírus, com indicadores do aumento do uso de álcool e outras drogas.

Ações que envolvam necessariamente formação de recursos humanos enfatizando as competências para atuar em saúde mental é imperativo. Para as Américas espera-se um projeto unificado entre governos, norteado pelas diretrizes da Reforma Psiquiátrica e calcada no modelo de atenção psicossocial. 


\section{Referências}

1. Barros S. Concretizando a transformação paradigmática em saúde mental: a práxis como horizonte para a formação de novos trabalhadores. Tese (Livre-Docência). São Paulo: Escola de Enfermagem da Universidade de São Paulo; 2004. 2. Organização Pan-Americana de Saúde; Organização Mundial de Saúde. Declaração de Caracas. Caracas: OPAS; OMS; 1990.

3. Organization of American States. Report on drug use in the Americas, 2015. [Internet]. 2015 [cited 2020 Nov 20]. Available from: http://www.cicad.oas.org/oid/pubs/druguseamericas_eng_web.pdf

4. Ceccim RB. Continuing education in health: ambitious and necessary challenge. Interface (Botucatu). [Internet]. 2005 [cited 2020 Nov 20];9(16):161-77. Available from: http://www.escoladesaude.pr.gov.br/arquivos/File/textos\%20 eps/educacaopermanente.pdf

5. Silva NS, Esperidião E, Cavalcante ACG, Souza ACS, Silva KKC. Desenvolvimento de recursos humanos para atuar nos serviços de saúde mental. Texto Contexto Enferm. [Internet]. 2013 [Acesso 22 nov 2020];22(4):1142-51. Disponível em: https://www.scielo.br/scielo.php?script=sci_arttext\&pid=S0104-07072013000400033

6. Bolzan LM, Hoff LR. Política de drogas e direitos humanos: avanços e desafios para a consolidação da reforma psiquiátrica brasileira. Cad Saúde Pública. [Internet]. 2018 [Acesso 22 nov 2020];10(25):96-117. Disponível em: https://periodicos.ufsc.br/index.php/cbsm/article/view/69631

7. Loch AA, Gattaz WF, Rössler W. Mental healthcare in South America with a focus on Brazil. Curr Opinion Psychiatry. 2016;29(4):264-9. doi: https://doi.org/10.1097/YCO.0000000000000259

8. Patel V, Saxena S, Lund C, Thornicroft G, Baingana F, Bolton P, et al. The Lancet Commission on global mental health and sustainable development. Lancet. 2018;392(10157):1553-98. doi: https://doi.org/10.1016/S0140-6736(18)31612-X

Autor Correpondente: Elizabeth Esperidião

E-mail: betesper@ufg.br

(i) https://orcid.org/0000-0002-9284-6243
Copyright $\odot 2021$ SMAD, Rev Eletrônica Saúde Mental Álcool Drog. Este é um artigo de acesso aberto distribuído sob os termos da Licença Creative Commons CC BY.

Esta licença permite que outros distribuam, remixem, adaptem e criem a partir do seu trabalho, mesmo para fins comerciais, desde que the atribuam o devido crédito pela criação original. É a licença mais flexível de todas as licenças disponíveis. É recomendada para maximizar a disseminação e uso dos materiais licenciados. 